\title{
MEMORIA, ICONOGRAFÍA Y PAISAJE: A PROPÓSITO DEL USO DE LA FOTOGRAFÍA COMO FUENTE GEOGRÁFICA
}

\author{
Juan Manuel Suárez Japón \\ Universidad Pablo de Olavide (Sevilla)
}

\section{RESUMEN}

La memoria es una facultad humana de inequívoca importancia en el manejo de los conocimientos. Los localiza temporal y espacialmente y deviene un factor esencial de nuestro reconocimiento, tanto individual como socialmente: "memoria personal versus memoria colectiva". a) Una de las opciones metodológicas de la Geografía, la llamada "histórica", en la que este trabajo se inserta, procesa las distintas fuentes y datos del pasado para alcanzar explicaciones del presente. b) De entre ellas, la fotografía ha alcanzado un valor relevante especialmente en el análisis de procesos de cambios paisajísticos veloces, los que es posible disponer de "series fotográficas" capaces de fijar el proceso en imágenes, trasuntos fieles de la realidad. c) Desde esas perspectivas metodológicas, se presente el estudio de un caso: la orilla del Guadalquivir por Coria del Río (Sevilla)

Palabras claves: Paisaje, Guadalquivir, geografía histórica, Coria del Río, Sevilla, fotografía, imagen.

\section{ABSTRACT}

Memory, iconography and landscape: a purpose of using photography as a geographic source

The memory is a human faculty of clear importance in the management of knowledge. It locates them temporally and spatially and becomes an essential factor for our identity recognition, both individually and socially: "personal memory versus collective memory". a) one of the methodological options of geography, the "historical" call in which this work is inserted, processing the various sources and data of the past to achieve the present explanations. b) among them, photography has reached a clear value especially in the analysis of processes of landscape changes fast and in cases in which it is possible to have "photographic series" that is able to set the process in pictures, faithful transcripts in reality. c) from those methodological perspectives, will present a case study: the banks of the Guadalquivir by Coria del Río (Seville).

Keywords: landscape, Guadalquivir, Historical geography, Coria del Río, Sevilla, photography, image.

\section{SOBRE LA MEMORIA Y EL PAISAJE}

La memoria es la facultad humana que manifiesta nuestra capacidad "psíquica por medio de la cual se retiene y recuerda el pasado" (RAE), o sea, la que nos permite "localizar hechos pasados como pasados". Sus aportes generan "inventarios" de hechos y datos localizados en ese tiempo pasado a los que genéricamente llamamos "recuerdos". Éstos se nos van acumulando, -con diversos grados de intensidad-, y construyen lo que podríamos llamar nuestro "sumatorio vivencial", esencial instrumento para situarnos en la realidad, para percibirla e interpretarla, para hacerla comprensible para nosotros mismo y para los demás. García Márquez lo sintetiza admirablemente en la introducción de sus "memorias": "la vida no es la que uno vivió, sino la que uno recuerda y cómo la recuerda para contarla",(García Márquez, 2004).Como es obvio, "este sumatorio" incluye datos territoriales o paisajísticos, en suma, pueden referirse también a las dimensiones espaciales en las que nuestras vidas transcurren.

La génesis de nuestros conocimientos debe mucho a sus conexiones con la memoria. De un lado, con la memoria subjetiva, la que en cada uno de nosotros actúa como uno de los soportes básicos del aprendizaje. De otro, con la memoria entendida en un sentido más colectivo o social, capacitada no sólo

Contacto: jmsuajap@gmail.com 
para producir "el conocimiento de cada uno", sino "el conocimiento", es decir, un superior estado de certeza acerca de los hechos con los que se conforman nuestra realidad presente y pasada. Este "conocimiento" alcanzaría significados compartidos, construido a partir de interpretaciones comunes de la realidad por parte de colectivos concretos. Trascendiendo al individuo, esta acción de la memoria conduciría a la creación de un cierto "saber objetivado", es decir, a definir lo que llamamos "memoria colectiva", en la que se integran hechos del pasado dotados de cierto valor simbólico, a partir de los cuales se crea ese "conocimiento compartido" sobre la realidad que es asumido por todos con significados idénticos.

Como es sabido, esta "memoria colectiva" posee una gran capacidad para vertebrar a una colectividad, -local, regional o nacional-, en torno a esa interpretación común de los mismos hechos. Por tanto, esta dimensión de la memoria exigiría una cuidadosa decantación de sus componentes, crear un "inventario selectivo", en el que se integrarían sólo algunos hechos del pasado, -recuerdos"-, referidos a personas, acciones, sucesos o imágenes simbólicas. Y entre ellos estarían también aquellos capaces de señalarnos esas continuidades significativas que siempre subyacen, -de forma más o menos percibida-, en los cambios que afectan a las vidas individuales y colectivas y a las dinámicas paisajísticas y territoriales. En todo caso, un criterio básico para esta "selección" habría de ser, precisamente, que los datos incorporables fueran interpretados con similares valoraciones por todos, de suerte que ese "inventario selectivo" se convertiría en un elemento fundamental de la identificación interna y externa del grupo humano en cuestión.

Si la primera de esas acepciones de la memoria nos remite a ámbitos de pura subjetividad, la segunda, nos introduciría en una dimensión de superior importancia, al menos como posible fuente de conocimiento. En ella los recuerdos meramente individuales dejarían de serlo para revestirse de valores abstractos, "conceptualizantes", al ser asumidos como propios por una determinada comunidad social. No sería aventurado afirmar que es así como se construye la memoria de los pueblos y como se han construido algunas formas básicas de las llamadas "culturas populares", en sus distintas escalas territoriales, desde las locales hasta las actuales formas culturales de la nueva sociedad global. Y ese mismo trayecto, el que va desde cada percepción individual hasta ese superior nivel de la abstracción, sería una parte sustantiva del proceso que en cada uno de nosotros va desde la "la información al conocimiento".

Este significado de la memoria, -más colectiva y abstracta-, se recoge también en los diccionarios de nuestra lengua. Se define ahí a la memoria como referida a ciertas experiencias biográficas o a sucesos ocurridos en un determinado ámbito o comunidad, -desde los cataclismales a los festivos-, que dejaron su "impronta indeleble", "recuerdo imborrable" para las personas, los espacios o las sociedades que los vivieron. Coloquialmente, se dice de éstos que fueron hechos que "han quedado en la memoria". Luego, la acción mitificadora que suele aportar el paso del tiempo, los convertiría en materiales a partir de los cuales se realizaría la construcción de la historia común. Es por ello por lo que ese legado de la "memoria compartida" deviene finalmente en fuente de conocimiento, que aporta respuestas no sólo para las interrogantes más trascendente, - "quienes somos, de dónde venimos..."- , sino también para esas otras que nos interrogan sobre el sentido de nuestras acciones o de nuestras creencias, las que descifran el origen de los términos que usamos para designar a los lugares, o en fin, aquellas que buscan saber cómo se han formado los paisajes que nos acogen.

Sostenemos ahora que estas posiciones metodológicas, -ya contrastadas para fenómenos desarrollados en plazos temporales de larga duración-, también son adecuadas para analizar situaciones geográficas o realidades paisajísticas que han sido frutos de cambios mensurables en escalas de observación ajustadas al "tiempo humano". Por ejemplo, las que han sucedido en algunos espacios periurbanos en expansión, ahí donde se han colonizado espacios y se han creado, -ante nuestra propia mirada-, paisajes que al poco tiempo se convirtieron en los nuevos "envoltorios" de nuestras vidas. En definitiva, lo que queremos resaltar es que la memoria, -individual o colectiva-, justamente porque nos aporta una mirada sobre las cosas pretéritas, es fuente válida para el conocimiento de hechos geográficos, de paisajes nacidos tras fuertes mudanzas cuyas causas, agentes y resultados pueden seguirse con el mero ejercicio de esa facultad humana de conocer y de recordar.

El análisis de esas mudanzas paisajísticas nos enseña también acerca de otro hecho de no menor importancia: el ritmo con el que las percepciones, tanto individuales como colectivas, digieren y asumen los cambios y cómo integramos de inmediato "lo nuevo" en los cotidianos mecanismos de nuestras vidas. Tal vez este sea uno de los rasgos que pueda predicarse de la sociedad contemporánea: estar afectada por un ritmo veloz e irreflexivo de consumo del tiempo y del espacio, de asunción de los cambios que se producen en nuestros entonos paisajísticos, de suerte que tendemos a pensar que las realidades que nos envuelven son fruto de procesos inevitables, ignorando los mecanismos y los intereses que los han 
producido. Quizás por ello, es una obviedad insistir en que en tales casos es donde más precisa se hace la memoria, donde más valor poseen los "recuerdos", que se convierten en una valiosa "fuente" para toda investigación geográfica interesada en explicar racionalmente los rasgos del presente.

Y aunque son muchos los instrumentos a través de los cuales ese pasado inmediato puede ser retenido y evocado, nosotros nos proponemos resaltar, en particular, el valor de uno de ellos: la fotografía.

\section{EL VALOR DE LA IMAGEN}

La asociación que proponemos entre la memoria y los materiales fotográficos pretende ser también una reconsideración del valor asignado a la fotografía en los análisis geográficos, superando una visión que tiende a entenderlos como meros ornatos de los textos, -el viejo concepto de "ilustración"-, de un simple apoyo a las descripciones. Ha sido el modo habitual en que la Geografía ha usado las imágenes fotográficas. Nosotros sostenemos aquí la convicción de que, -para ciertos procesos y en ciertos casos-, la fotografía adquiere valor como fuente de conocimiento geográfico. Tras más de siglo y medio de existencia, ya es posible disponerse de series de imágenes retrospectivas y por ello, la fotografía debe ser entendida como fuente geográfica en sí misma, dotada de un potencial que sólo espera a ser aprovechada para rendir sus frutos. Acerca de esta cuestión son especialmente ilustradoras las afirmaciones de F. Quirós Linares, señalando, como una carencia, el poco uso que los geógrafos hemos hecho de la fotografía como apoyaturas de nuestras descripciones: "Algo similar ocurre en Geografía. Un simple repaso a las revistas de nuestra disciplina nos pondría ante la misma evidencia. No son pocas aquellas en las que se manifiesta el dominio adquirido por muchos profesionales de la Geografía en el difícil arte de hacer plenamente inteligible la realidad descrita sin ofrecer una sola imagen. Acaso se deba a que, metodológicamente, ese no es un requisito de obligado cumplimiento, aunque también pudiera ser fruto del hecho de que, en realidad, lo descrito y explicado no lo es desde una perspectiva propiamente geográfica".

Quirós Linares ha recordado que toda la responsabilidad de este "olvido" no deba ser atribuible a los geógrafos, porque la corriente de interés que hoy existe por la fotografía histórica y la propia posibilidad de acceso a ciertas colecciones, -en algunos casos de existencia desconocida hasta hace poco-, es algo que no se tenía hasta comienzo de los años ochenta del pasado siglo. Así pues, desde esa coincidencia inicial acerca del insuficiente manejo que los geógrafos hemos hecho de las fotografías, reafirmamos la tesis de que en el tiempo presente, en el análisis de determinados procesos territoriales no es aconsejable seguir relegando las imágenes fotográficas a ámbitos secundarios. Por el contrario, la fotografía reclama ser tenida en cuenta como una más de las posibles fuentes que manejamos habitualmente en nuestras descripciones geográficas.

Por otra parte, es un hecho cierto que cada época histórica ha usado medios y técnicas propias de reproducción de la realidad y que éstos han ido cambiando con el paso del tiempo y con el sucesivo avance de las tecnologías puestas al servicio de tales fines. Pero más allá de las diferencias entre unos y otras, en el fondo, siempre estaríamos hablando de lo mismo: son modos o técnicas que manejan materiales usados por el hombre en su utópico intento de detener el tiempo, de retener, -para recordarlo y/o para transmitirlo-, un presente inevitablemente fugaz, efímero, inaprensible. Los hombres han aspirado siempre a disponer de esos instrumentos que le permitieran "inmortalizar", -salvar de la desaparición y del olvido-, a individuos, a situaciones diversas, a paisajes cercanos o lejanos, generando así materiales que se acaban convirtiendo en fuentes esenciales para la reconstrucción de un presente llamado inevitablemente a convertirse en pasado. De otro lado, éste es, además, un proceso que, en nuestros días, parece haberse acelerado.

En la actualidad, recuperamos la mayoría de los hechos "memorables" usando determinadas informaciones, -documentales, cartográficas, bibliográficas, estadísticas, iconográficas, etc.-, convergentes todas ellas en su capacidad para mostrarnos rasgos del pasado. Ese es el carácter que unifica a la escritura jeroglífica, a los pergaminos y a los documentos epigráficos, a los restos arqueológicos, a las modestas edificaciones rurales o a las grandes arquitecturas que manifiestan el poder de sus dueños, o también las plurales aportaciones de la creatividad pictórica, musical o literaria. Y por supuesto, lo hacen con multiplicada capacidad los poderosos soportes audiovisuales que nos trajo la evolución técnica, entre los cuales la fotografía, -a través de sus muchas modalidades y tipologías-, siempre tuvo una importancia que no ha hecho sino acrecentarse con la aparición de las nuevas técnicas digitales. Todas esas "informaciones" comparten su común condición de vías para el conocimiento del pasado y fuentes para su investigación, 
si bien es cierto que no todas han tenido ni la misma importancia ni idéntica valoración en el ámbito estrictamente académico.

Debe advertirse que estos planteamientos nos conectan con dos sólidas líneas epistemológicas, básicas en el desarrollo de la Geografía Humana. De una parte, a través de "la memoria" aceptamos la validez de los procesos genéticos y evolutivos en la explicación de los hechos resultantes, es decir, explicamos las realidades geográficas o paisajísticas desde el conocimiento de su gestación, en línea con los postulados de la Geografía Histórica afirmados por Gil Olcina al señalar que "a menudo el análisis genético constituye vía insustituible para interpretar paisajes rurales o urbanos" (1987). De otra parte, es imposible ignorar que la memoria, -sea individual o colectiva-, es una construcción cargada de subjetivismo. Por tanto, la incorporación de la memoria al proceso cognitivo y a la praxis investigadora supone aceptar la validez de la vía subjetiva al conocimiento, -la que hemos dado en llamar Geografía de la Percepción-, y afirmarla frente a las reticencias o las negaciones que acerca de ella se ha venido sosteniendo desde otras tradiciones científica de muy potente asiento en la comunidad de geógrafos.

Conjugando ambas visiones, lo que tratamos de reconocer es que esta conexión entre la memoria, -en este caso sostenida en el uso de la fotografía-, y el análisis geográfico se hace especialmente conveniente en situaciones afectada por cambios paisajísticos profundos producidos en espacios temporales cortos. Todo ello, naturalmente, sin que ello suponga desdeñar la importancia de las otras fuentes del análisis geográficos que, manejadas con cierta inteligencia, pueden ser sumatorias y no contradictorias para las intenciones del investigador. Ese es el marco conceptual en el que asentamos esta aportación resaltando la utilidad y el creciente valor que la imagen puede alcanzar para el análisis de procesos territoriales y muy especialmente a través del manejo de series fotográficas temporales.

\subsection{El creciente protagonismo de la fotografía}

Es un aserto aceptado que el tiempo presente se ha acomodado a un cotidiano uso de la imagen y que ésta ha invadido todos los rincones de las actividades humanas, desde íntimas a las puramente profesionales y también a aquellas que se pueden aplicar a nuestro trabajo docente e investigador. Ha impregnado los hábitos de una ciudadanía que ha incorporado la imagen a sus vidas hasta extremos que hace pocos eran inimaginables. Hemos pasado de un tiempo en que hacernos una fotografía era un acontecimiento singular a otro en que todo cuanto sucede se fotografía. Por ello, es inevitable que nuestras metodologías investigadoras y nuestros proyectos docentes se apoyen en ellas, más aún con el horizonte que hoy abren las TIC. En definitiva, vivimos en una situación en la que nos resulta muy difícil pensarnos en entornos o actividad en las que las imágenes no se hagan presente de un modo notorio: "somos una sociedad de la imagen", se escucha con frecuencia en las conversaciones cotidianas.

Naturalmente, esta situación no está carente de aspectos negativos, tal como se desprenden en las palabras de Susan Sontag (1996): "las sociedades industriales transforman a sus ciudadanos en un puro vaciadero de imágenes". Nos alertan sobre los excesos en su utilización y su consumo, que pudieran estar conduciéndonos a una trivialización de sus significados y a una desvaloración de sus utilidades. La comprometida pensadora no reparó incluso en señalar que las sociedades modernas estaban afectadas por la existencia de una "irresistible contaminación visual". En todo caso, destaquemos que esta omnímoda presencia de la imagen en nuestras vidas acentúa su conexión con la memoria y la construcción de conocimiento. La dinámica nos ha conducido a una integración plena de las imágenes en la realidad cotidiana, de suerte que, a diferencia de otros tiempos, todos los hechos de nuestro presente, -individual o social-, quedan retenidos en imágenes. La sociedad contemporánea es una "sociedad retratada" en términos no equiparables, -por obvias razones-, a ninguna otra época de la Historia humana.

El fuerte ritmo con el que los acontecimientos se suceden en la sociedad actual nos ha conducido a la evidencia de que el tiempo presente parece acortarse al tiempo que se multiplican las imágenes que tienen la virtud de "convertir en pasado" todo lo que "apresan". De esta suerte, hemos otorgado a la imagen un poder gracias al cual creemos dominar al tiempo convirtiendo de inmediato el presente en recuerdo. Así pues, tanto en nuestra dimensión personal como en nuestra tarea investigadora, estamos sometidos a esa dialéctica constante de recepción, selección y "amortización" de datos de la realidad formulados en imágenes, sintiéndonos incluso empujados por una sobreabundancia tal que puede jugar en detrimento de nuestra capacidad de reflexión.

Sin renunciar a lo que cada uno de estos aportes iconográficos significa, insistimos en centrarnos aquí en torno a uno de ellos, uno de esos "instrumentos de la memoria": la fotografía, a la que asignamos 
valores que la convierten en fuentes para el análisis geográfico, de una parte, a) porque son reproductoras fieles de la realidad, es decir, por su fiabilidad (Muñoz Molina, 1993); de otra, b) por la posibilidad de seguir evoluciones temporales de ciertos procesos apoyados en "series fotográficas" que serían equivalentes, por ejemplo, a las series estadísticas o climáticas, de tan inequívoca aceptación como fuentes geográfica.

\subsubsection{La fotografía como trasunto fiel de la realidad}

A la fotografía como testaferro fiel de la realidad se ha referido Muñoz Molina (1993) afirmando que "casi únicamente los fotógrafos han conservado intacta en nuestros tiempos la serenidad moral, la intensidad humana y la pasión por lo real que fueron materiales comunes de la pintura y la escultura hasta la frívola irrupción de las vanguardias". Es cierto que, tanto en sus dimensiones utilitarias como en la puramente artística, la fotografía ha sostenido su notoriedad social en ese apego a lo real al que alude el escritor andaluz, quien insiste en que "la fotografía nunca ha podido o nunca ha querido renunciar a lo real; en el fotógrafo hay un ansia tan poderosa de mirar y de descubrir el espectáculo incesante de la vida que puede curarlo de antemano de cualquier tentación de narcisismo", concluyendo al definir la fotografía como "un acto de atención, es decir, de humildad, pues solo permanece atento a lo que ocurre más allá de él".

Siendo todo ello poco discutible, admite ciertas precisiones en el sentido, -importante para nuestros puntos de vista-, de que no todas las fotografías poseen el mismo valor, aunque de todas pueda predicarse ese apego a lo real que las define (Yáñez-Polo, 2002). Aunque sea cierto que, como dice Sontag, "todas las fotografias aspiran a la condición de ser memorables, es decir, inolvidables", no todas tienen el mismo valor como fuente de conocimiento geográfico, ni a todas puede otorgárseles el mismo grado de objetividad. Porque la fotografía es "antes que nada, una manera de mirar. No es la mirada misma (Sontag, S, 1996). Por eso, donde esperábamos hallar una realidad objetiva podemos encontrarnos un acto de subjetividad. "Siempre habrá un porcentaje mínimo de subjetividad del cámara, una especie de vértigo del "subiectum" que provenía de la denominada "fascinación de la ficción"” (Nichols, B, 1997). De modo que, sin desdecirnos de esa virtud de la fotografía que es "la pasión por lo real", en su manejo como fuente de conocimiento geográfico conviene no olvidar una cierta prudencia, porque aunque pueda parecer que mirar sea un mero gesto natural, como señala Muñoz Molina (1993), la mirada puede ser "un oficio de infinita sofisticación intelectual", añadiendo que del mismo modo que "la literatura es una hipóstasis de la voz, la fotografía es la condensación o el paroxismo de la mirada".

El argumento nos sitúa ante un hecho básico para nosotros: el geógrafo que acuda a las fotografías como fuente ha de tener presente que cada una de ellas es una creación "del que mira" y que es sobre esa "creación" sobre la que él mismo habrá de proyectar "su propia mirada de geógrafo" para extraerle las informaciones que resulten útiles a los fines de su investigación. Ante el manejo de las fotografías el geógrafo deberá pues estar proyectando también su mirada particular, del mismo modo que lo haría si sus fuentes fuesen los documentos o textos literarios (Suárez-Japón, 2003) o las producciones pictóricas. Desde esos postulados, reformulamos tesis de la necesidad de dotar de valor a la fotografía como fuente geográfica, superando las funciones "ornamentales" que hasta ahora se les asignaron. Y todavía un último aspecto: como en otras fuentes de investigación geográfica, con las fotografías es preciso usar un adecuado criterio de selección, pues no todas poseen el mismo valor. Así, si bien las fotografías más antiguas suelen ser especialmente buscadas por su excepcionalidad y rareza o por la exclusividad del dato que ofrece, debe señalarse que la mera antigüedad no confiere a la fotografía su importancia como fuente. Este valor habrá de venir fundado en la capacidad que cada imagen tenga de trasladarnos datos que permitan hacer una lectura geográfica de los mismos.

\section{ESTUDIO DE UN CASO: LA ORILLA DEL GUADALQUIVIR EN CORIA DEL RÍO (SEVILLA)}

La onda de marea que marca el límite del estuario alcanza hasta Alcalá del Río, pero sólo aguas abajo de la ciudad de Sevilla se extiende el Guadalquivir navegable. Este discurre por una llanura sin apenas pendiente que permite su navegabilidad pero que definió sus escorrentías a través de diversos brazos o cauces, que describían amplios meandros y devenían en obstáculo para la propia navegación que permitían. El régimen pluviométrico irregular que le otorga el ámbito geográfico por el que discurre, le hacía alternar estiajes profundos y periodos de fuertes crecidas del caudal que sometían a sus frágiles orillas arcillosas a alternativos procesos de erosión y sedimentación que colmataban los fondos y hacían aún más compleja la navegación por sus aguas. Esta dialéctica, de base fisiográfica, define y explica al Guadalquivir y a la vida de los hombres que desde tiempos muy remotos se asentaron en sus márgenes. 
En este tramo navegable, a unos diez kilómetros aguas abajo de la ciudad de Sevilla, se localiza el tramo de la ribera de la que nos ocupamos. Se trata de la orilla urbana de Coria del Río, el municipio ribereño de más fuertes vínculos con el Guadalquivir y sus modos de vida (Suárez-Japón, 2000). Como los otros núcleos del borde oriental del Aljarafe, Coria del Río se asentó en lo alto del cerro que bordeaba al río, pero a diferencia de los demás, creció bajando al llano y ordenando su caserío de forma paralela al cauce, del que durante siglos sólo le separaba el lecho mayor de las inundaciones (Suárez-Japón, 1985; 2000). El núcleo urbano quedó vinculado, -física y humanamente-, a la vida en la orilla aunque limitado por los reiterados pulsos erosivos que en ella establecían las aguas y las tierras. Todo ello acentuado por el hecho de que la orilla se sitúa en el frente cóncavo de un viejo meandro, el llamado de La Merlina, - "cortado" en 1795-, lo que la convertía en el escenario seguro de las agresiones erosivas del Guadalquivir (Suárez-Japón, 1985) (figura 1). Incluso después de eliminado el meandro, -el primero de los que serían eliminados en el Guadalquivir a lo largo del siglo XIX (Moral, L. de, 1991)-, la orilla no superó ese carácter de espacio de confrontación con el río (Castillo, A, et al., 2012). De este modo, tras cada desbordamiento la orilla experimentaba daños visibles que, con el paso del tiempo, vinieron a convertirse en una constante preocupación para el pueblo (Suárez-Japón, 2012).

Figura 1

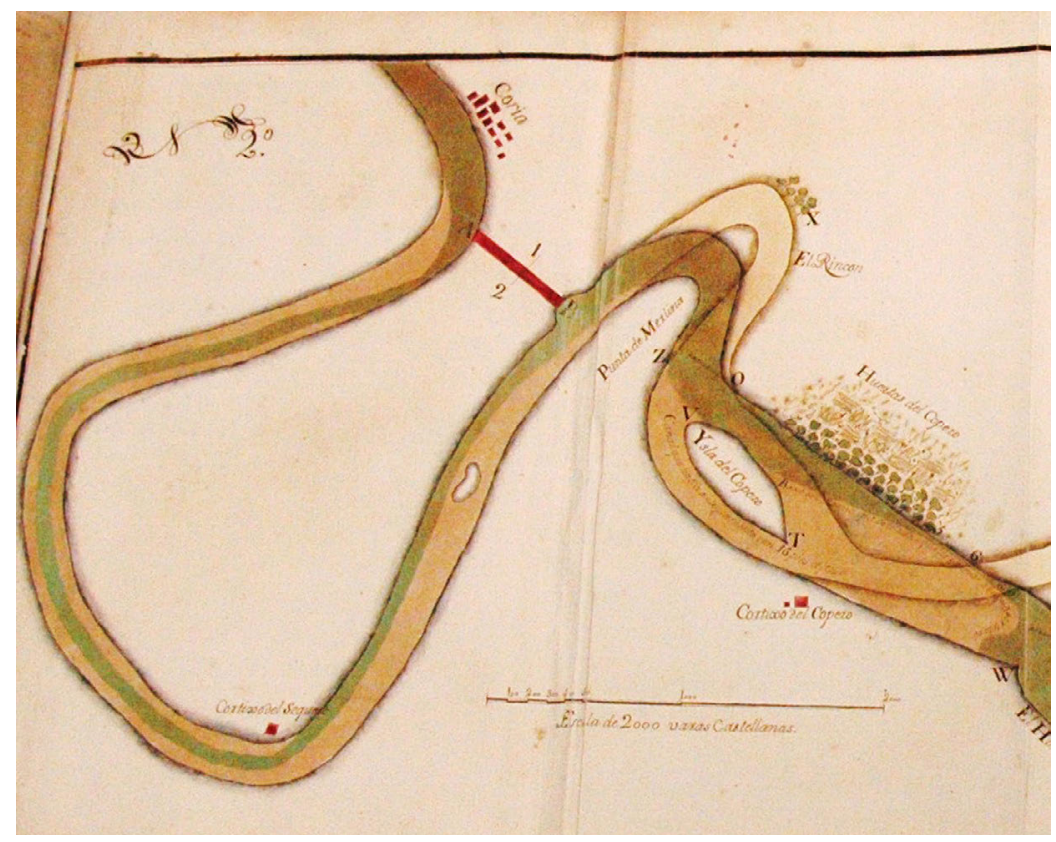

Los Boletines de Información Municipal (BIM), que comenzaron a editarse desde 1909, nos permiten constatar la preocupación por el creciente deterioro de la orilla en los sectores próximos a la carretera que unía al pueblo con Sevilla. Es una constante en toda la centuria. Los sucesivos acuerdos capitulares nos van dejando ecos de la misma, sin que a esa preocupación siguiesen correlatos de obras o reformas para paliar los peligros. Sólo en los comienzos de los años treinta del siglo XX se produjeron algunas mejoras en estos sectores, vinculadas a las obras que exigieron la implantación del trazado del "ferrocarril secundario", -inaugurado en mayo de 1932-, un tranvía que unió a los pueblos de este borde oriental de Aljarafe con la ciudad de Sevilla. Su trazado se hizo alejándose del contacto con el cauce y dejando entre ambos una carretera que fue deteriorándose (figura 2) por la constante acción erosiva del río (figura 3). Así mismo, una parte del caserío coriano llega a mitad del siglo manteniéndose en una crónica situación de riesgo (figura 4) por los perseverantes asedios del Guadalquivir.

Unos años antes, en 1938, la comisión gestora del Ayuntamiento coriano promovió el desvío del punto de desembocadura del arroyo Pudio, un afluente del Guadalquivir cuya dinámica acentuaba la dimensión de las riadas. Y en 1937 se había solicitado la "construcción de un muro de defensa en el trozo de la carretera que linda con el Batán". Junto a esto y a lo largo de todo el siglo, se producen peticiones de ayudas a las "perentorias necesidades de la población". Durante los años 1944 y 1945 se registran peticiones semejantes por parte del Cabildo coriano sin respuesta alguna y en 1950, tras la gran riada de 1947, 
calificada por Nicolás Salas como "una de las más importantes del siglo" (Salas, 1994), vuelven a reclamar "medidas urgentes y necesarias para evitar los daños causados por la corriente del río en la zona de entrada de la población, poniendo en peligro la carretera general y un gran número de viviendas" (BIM, septiembre 1950). Pese al tono, casi desesperado, de las peticiones y a los sucesivos desbordamientos que el Guadalquivir tuvo en los años 1951 y 1952, no será hasta finales de esta década cuando se iniciaron algunas obras reparadoras de la situación.

Figura 2

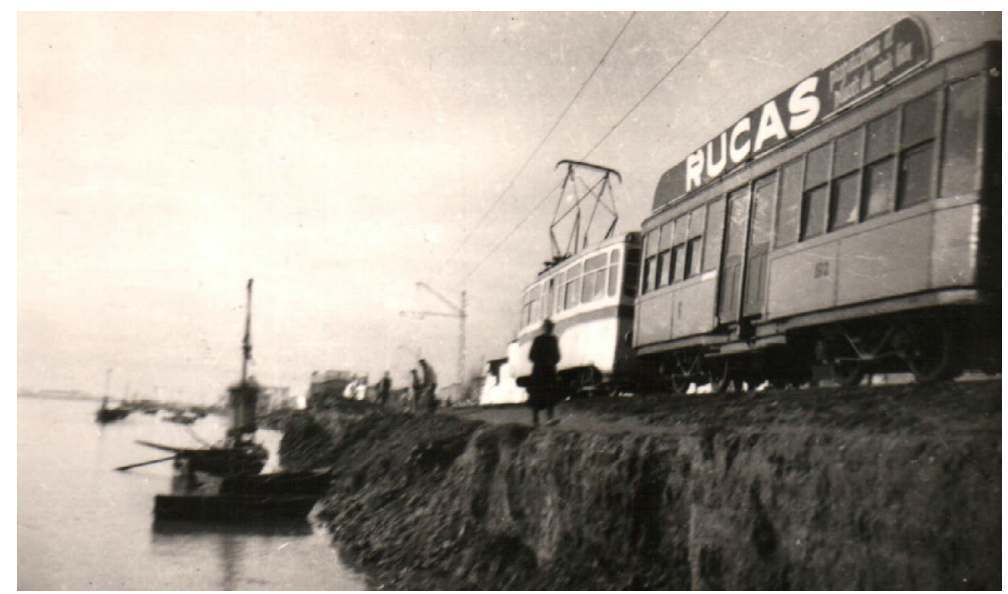

Figura 3

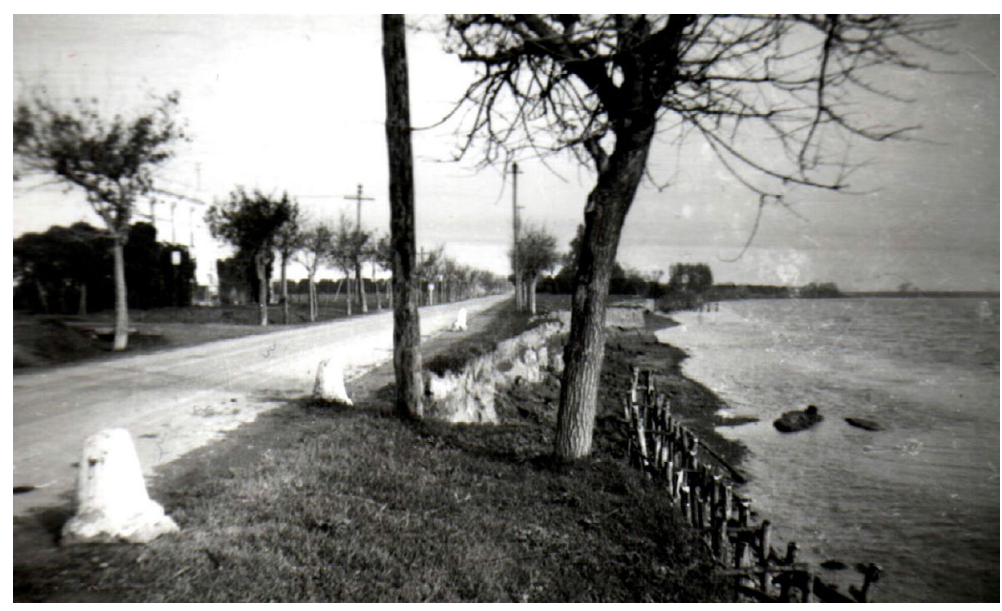

Figura 4




Nuevas riadas en 1955 habían acrecentado los daños en esta orilla derecha y se solicitó al Ingeniero de Obras Públicas de la provincia "la urgente defensa de la margen del río", en la que se habían dañado también las casas del barrio de los pescadores (BIM. Marzo 1955). Tras dilatadas esperas, en 1959 fueron adjudicadas obras de defensa de la margen que comenzaron a ejecutarse entre 1960 y 1961. Consistieron en la colocación de 3000 plantones de eucaliptos con las que se formaron empalizadas rellenas de piedras y entrelazadas con redes metálicas (figuras 5 y 6 ). Es curioso constatar que en estas fechas tan tardías se decidiesen obras sujetas a técnicas que ya habían sido recomendadas en algunos de los proyectos de mejoras del río que se planteaban desde el siglo XVIII (Castillo, A. et al., 2012). No obstante, esta década de los sesenta señala un umbral de cambio, basado en dos factores externos: de una parte, a partir de 1965 el tranvía a Sevilla dejó de funcionar y los suelos de su trazado viario fueron recuperados para el dominio público, pudiendo la carretera ampliarse por ellos y, de ese modo, "alejarse del río"; por otra, la regulación de los caudales del Guadalquivir que se efectuaba desde las grandes presas de Alcalá del Río y de Cantillana, -ambas situadas aguas arriba de la ciudad de Sevilla-, (Bernal, AM. 1994) controlaron el flujo de las aguas haciendo más "previsibles" las riadas, bien que al alto precio de producir efectos dañinos e irreversibles en ciertas actividades pesqueras de este tramo del Guadalquivir (Algarín, S. 2000).

Figura 5



Figura 6

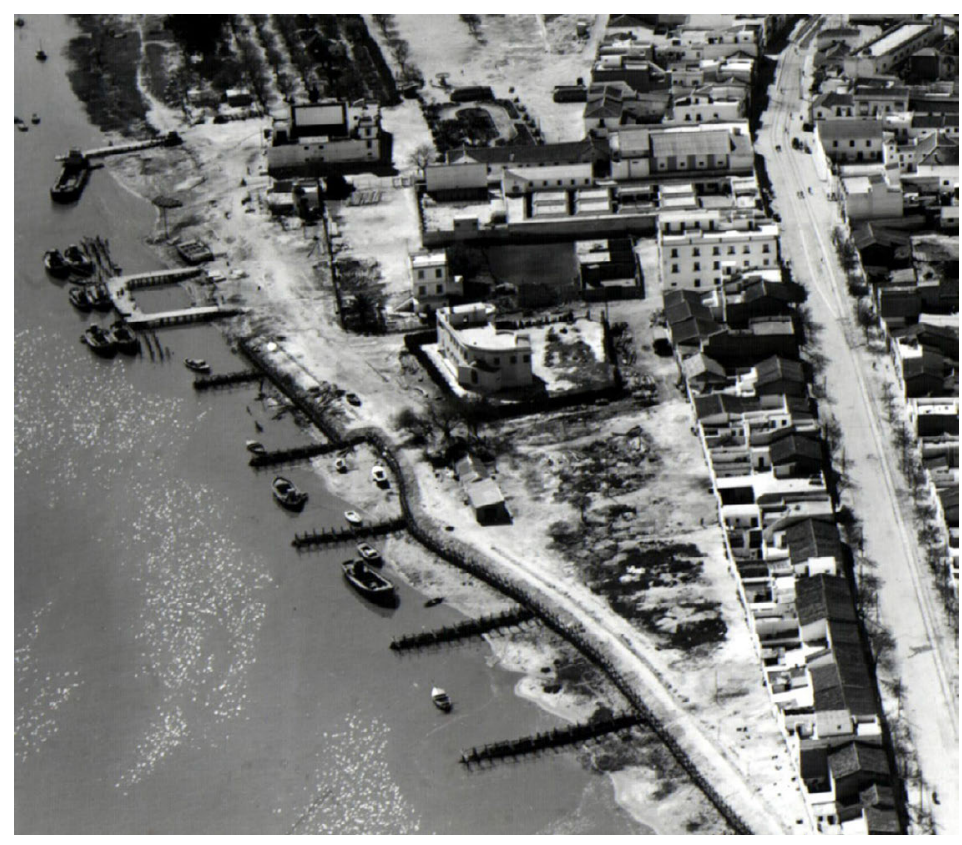


La década de los sesenta, pese a todo, finalizaría sin que los crónicos problemas de la protección de la orilla se hubiesen abordado, salvo algunas soluciones provisionales, -del tipo de las estacas que luego se generalizaron en todo el bajo río-, frente a las cuales la constancia erosiva del Guadalquivir, una vez tras otra, resultaba vencedora. Durante años, el pulso con las "agresiones" del río obligó a periódicas reposiciones de las empalizadas de estacas lo que certificaba la conciencia de su limitada validez. Las primeras corporaciones democráticas serían las que, mediados ya los años ochenta, retomarían las peticiones al gobierno central para dar al Guadalquivir otras respuestas, especialmente en el tramo de la orilla más amenazada, la que va entre la huerta de "Villa Pepita" y la desembocadura del arroyo Pudio. La respuesta aun tardó en producirse, pero finalmente el gobierno de España aprobó un Plan Integral de Protección de la Orilla y construcción de un Paseo Fluvial, cuya inauguración se produciría años después, en marzo de 1994. El resultado ha sido no sólo la solución a los crónicos problemas erosivos de la orilla del Guadalquivir coriano, sino la creación de "un nuevo paisaje", que sólo tiene treinta años y que todos han hecho suyo, hasta el punto de que sólo la memoria de quienes lo hemos vivido, -con el esencial apoyo de las imágenes fotográficas-, nos permiten entenderlo y localizar en él elementos de continuidad en el seno de cambios tan profundos (figura 7).

Figura 7

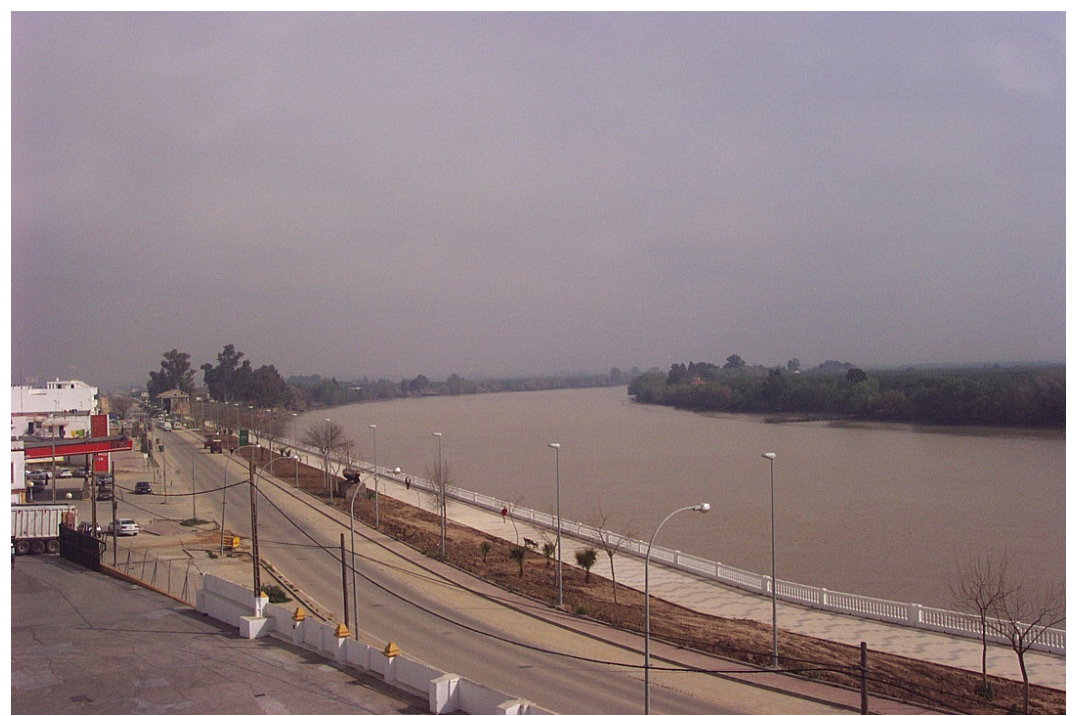

El proceso de implantación del citado Plan de Protección y de la paralela construcción de un Paseo Fluvial fue muy dilatado, a causa de sus innegables dificultades. En síntesis, la orilla a proteger se dividió en dos sectores. El primero, sometido a superiores embates de las aguas, -desde la huerta hasta Punta Arenas-, fue abordado mediante la instalación de una red de grandes paneles de aceros perpendiculares, clavados en el fondo, con los que se construyó una "pared" que aislaba a la orilla del contacto directo con el río (figuras 8) del que se separa por un esbelto barandal. El otro sector fue sometido a un tratamiento diferente: mediante la "construcción" de unas rampas sobre la superficie de la orilla y hasta las aguas, en la que se depositaron telas asfálticas y una gruesa capa de piezas de hormigón (figura 9), -que no han evitado el afloramiento de un herbazal espeso-, rematadas con un murete continuo que recorría toda la orilla. Al otro lado del mismo y en todo el espacio transformado se habilitó el Paseo Fluvial (figura 10) convertido hoy en un espacio de ocios con unos intensos usos públicos.

Nada es ya como era. Un paisaje nuevo se extiende a lo largo de este tramo de la margen derecha del Guadalquivir por Coria del Río (figura 11). Sólo algunos elementos, como la Venta del Embarcadero (figuras 12 y 13), nos sirven hoy como elementos de continuidad y nos permiten reconocer los espacios e identificarnos a nosotros mismos. Las fotografías que reflejaban la situación de la orilla a mediados el siglo XX son hoy contempladas por los más jóvenes con perplejidad. Les cuesta creer que el espacio que hoy ven y en el que pasan su tiempo no haya sido siempre así. Es la ingenua trampa del paisaje: la falsa apariencia de eternidad que en cada momento nos transmite. Frente a ello, las series fotográficas nos permiten revelar las fases y las formas de su génesis al tiempo que una investigación más completa nos desvelará también las razones o los intereses que en su caso los promovieron. 
Figura 8

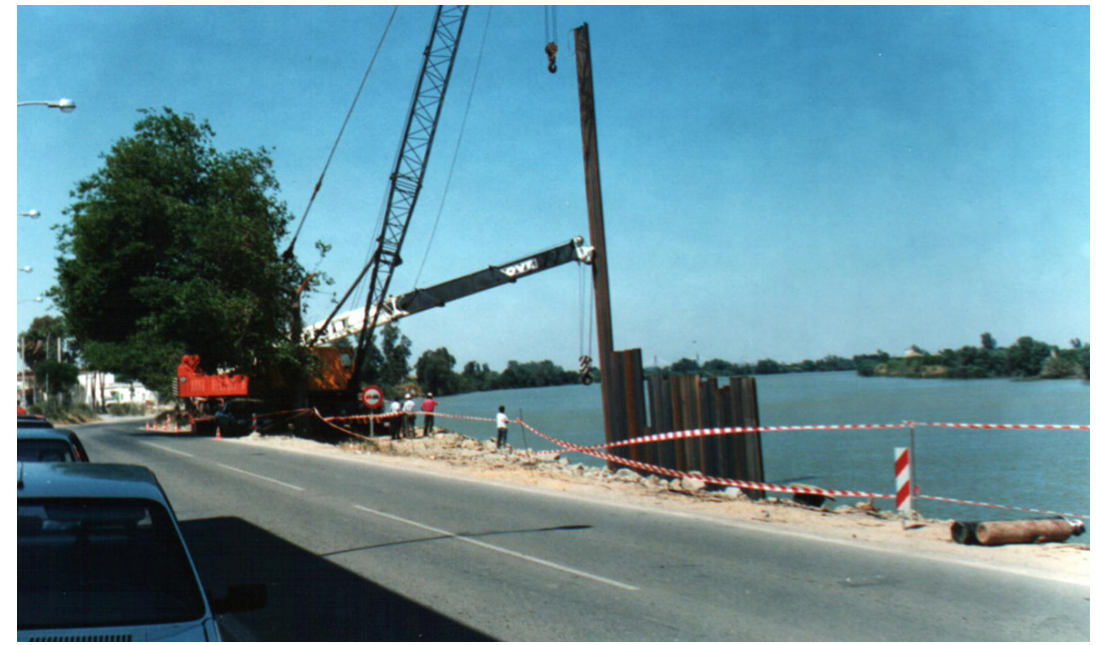

Figura 9

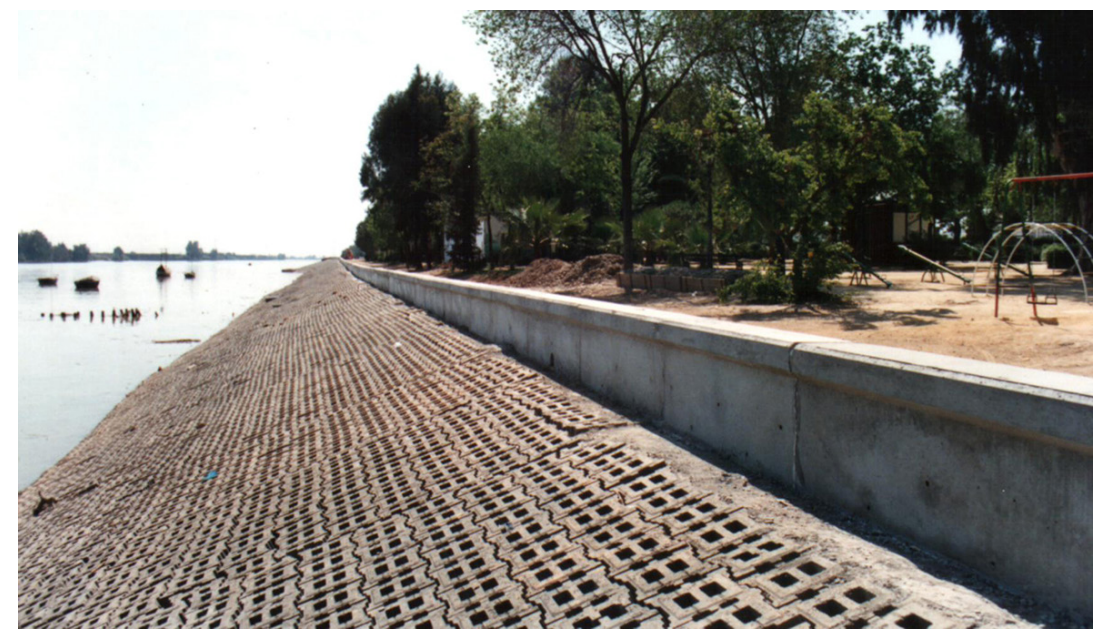

Figura 10

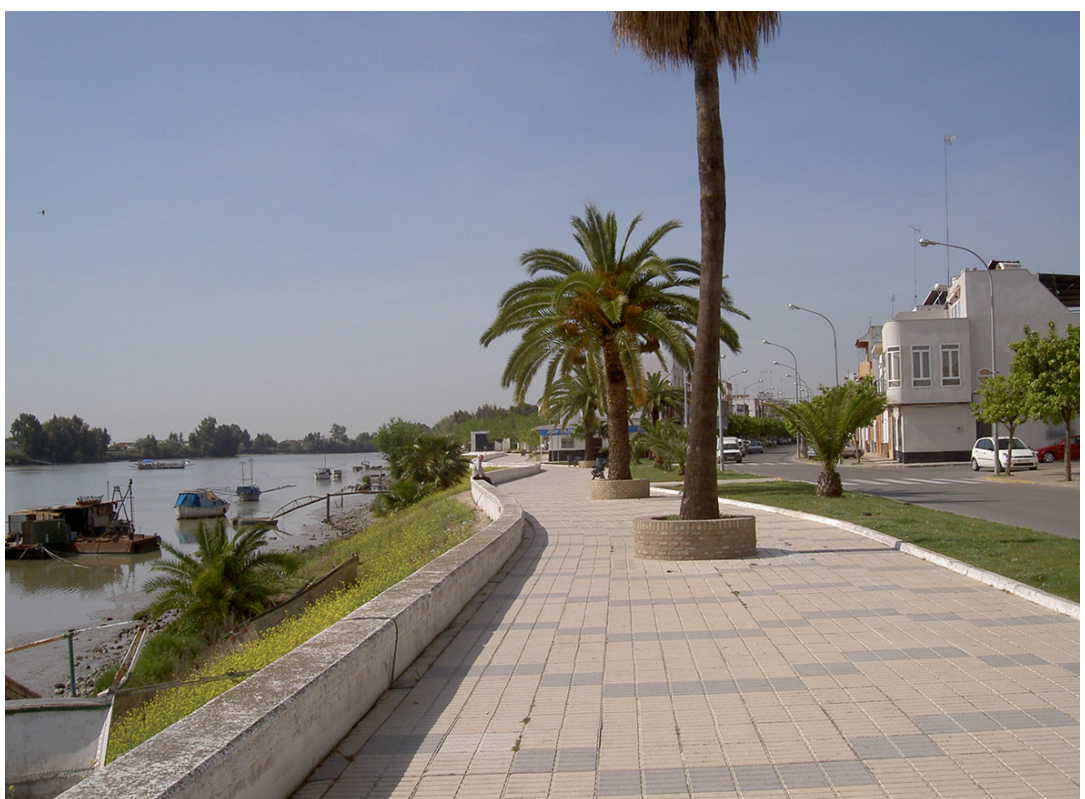


Figural1

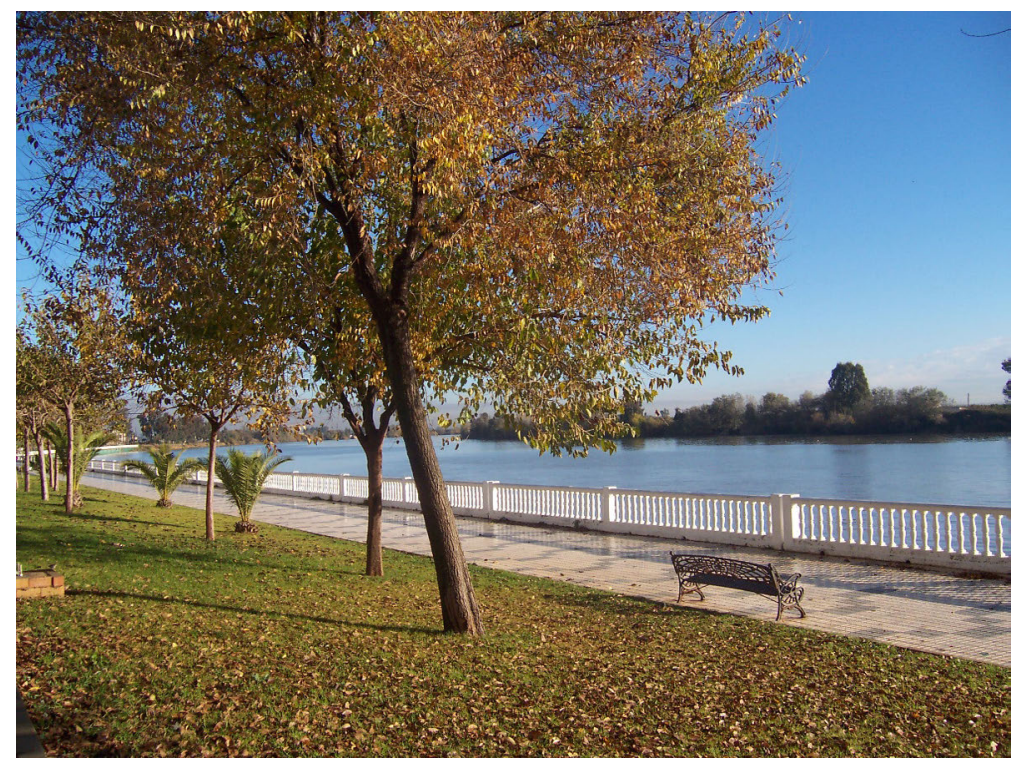

Figura 12



Figura 13

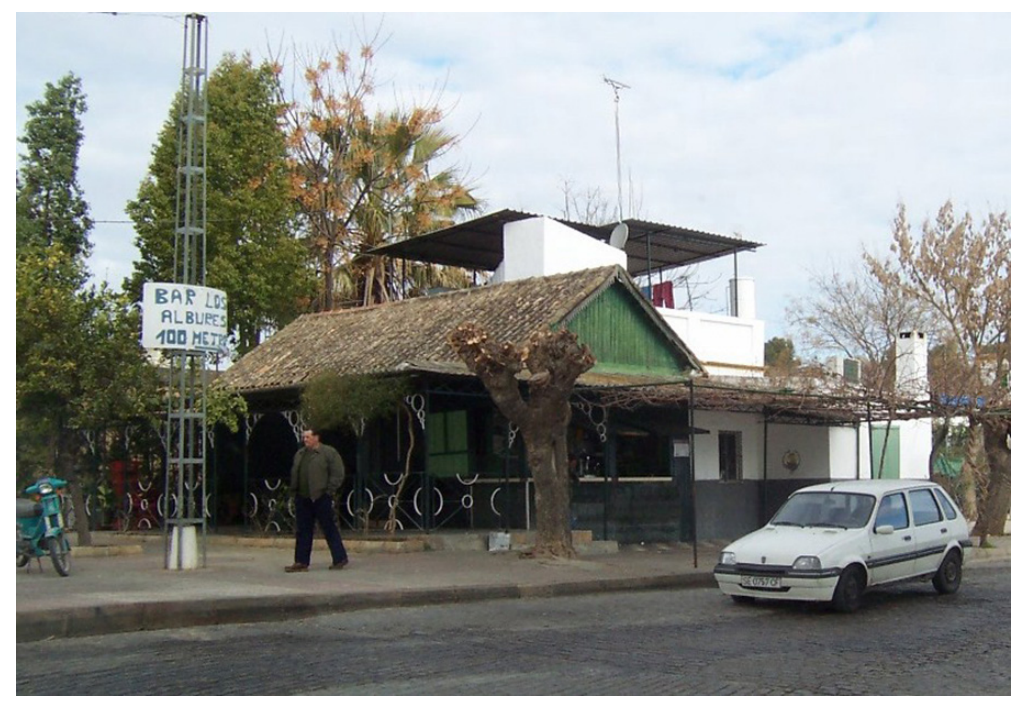




\section{BIBLIOGRAFÍA}

ALGARÍN, S. (2000): "La historia última de los esturiones del Guadalquivir", en Revista Azotea. No 13-13. Ayuntamiento de Coria del Río (Sevilla). págs. 18-57 más apéndice.

BERNAL, AM. (1994): "Historia de la Compañía Sevillana de Electricidad (1894-1993); en Compañía Sevillana de Electricidad: cien años de historia. Fundación Sevillana de Electricidad. Sevilla.

CASTILLO, A., et al. (2012): Sevilla y su río en el siglo XVIII. Un proyecto ilustrado para la mejora del cauce del Guadalquivir. Universidad de Sevilla. Sevilla.196 p. (más apéndice)

GARCÍA MÁRQUEZ, G. (2004): "Vivir para contarla". Mondadori-RBA. Madrid.

MORAL, L. de (1991). La obra hidráulica en la cuenca baja del Guadalquivir (siglos XVIII-XX. Universidad de Sevilla y Consejería de Obras Públicas. Junta de Andalucía. Sevilla.

MUÑOZ MOLiNA, A. (1993). Prólogo a Martín Morales. "Sostener la Mirada". Exposición fotográfica. Consejería de Cultura de la junta de Andalucía. Granada.

NICHOLS, B. (1997): La representación de la realidad. Cuestiones y conceptos del Documento. Paidós ed. Barcelona.

PALOMO, F. DE B. (1878): Historia crítica de las riadas o grandes avenidas del Guadalquivir en Sevilla. Francisco Álvarez Impresores. Sevilla (edición facsímil Colegio Oficial de Aparejadores y Arquitectos Técnicos de Sevilla. Sevilla. 1984).

QUIROS LINARES, F. (1992): "Fotografía Histórica y Geografía Histórica", en Treballs de la Societat Catalana de Geografía - N 33-34 - vol. VII.

GIL OLCINA, A (1987): "La Geografía Histórica en España; en La Geografía Española y Mundial en los años ochenta (Homenaje a Manuel de Terán). Universidad Complutense de Madrid. Madrid. pp 469-480

SALAS, N. (1994): "Sevilla en tiempos de María Castaña", Castillejos edt. 2 volms. Sevilla.

SONTAG, S. (1996): Sobre la fotografía. Edhas. Barcelona.

SUÁREZ-JAPÓN, JM. (1985): "La corta de La Merlina. 1795"; en Anales de la Universidad de Cádiz. II. Universidad de Cádiz págs. 295-310. (incluido también en Guadalquivir por Coria. Estudios geohistóricos. Autoridad Portuaria de Sevilla y Diputación Provincial de Sevilla.

SUÁREZ-JAPÓN, JM. (1985): "La distribución del poblamiento en el bajo Guadalquivir"; en El río. El bajo Guadalquivir. Consejería de Obras Públicas de la Junta de Andalucía. Sevilla. Págs. 138-143.

SUÁREZ-JAPÓN, JM. (2000): Guadalquivir por Coria. Estudios geohistóricos. Autoridad Portuaria de Sevilla y Diputación Provincial de Sevilla.

SUÁREZ-JAPÓN, JM. (2000a): "Las riadas del Guadalquivir en Coria: conflicto social y desarrollo urbano"; en Guadalquivir por Coria. Estudios geohistóricos. Autoridad Portuaria de Sevilla y Diputación Provincial de Sevilla. págs. 17-84.

SUÁREZ-JAPÓN, JM. (2003): "Geografía y Literatura en los escritos de viaje de José Manuel Caballero Bonald", en Boletín de la Asociación de Geógrafos Españoles (AGE). № 34 (Geografía y Cultura). Madrid. págs. 133-146.

SUÁREZ-JAPÓN, JM. (2012): "Sobre el río y las riadas que asolaban a sus pueblos y sus campos"; en CASTILLO, M.(2012). Sevilla y su río en el siglo XVIII. Un proyecto ilustrado para la mejora del cauce del Guadalquivir. Universidad de Sevilla. Sevilla.196 p (más apéndice). pags. 65-96.

YÁÑEZ-POLO, MA. (2002): Historia de la fotografía documental en Sevilla. ABC de Sevilla y Comisaría para el X Aniversario de la Exposición Universal. Sevilla. 310 p. 